This item was submitted to Loughborough's Research Repository by the author.

Items in Figshare are protected by copyright, with all rights reserved, unless otherwise indicated.

\title{
'Good' communication in schizophrenia: a conversation analytic definition
}

PLEASE CITE THE PUBLISHED VERSION

http://www.palgrave.com/page/detail/the-palgrave-handbook-of-adult-mental-health-michelle-oreilly/? sf1=barcode\&st1 $=9781137496867$

\section{PUBLISHER}

(C) Palgrave Macmillan, reproduced with their permission

\section{VERSION}

AM (Accepted Manuscript)

\section{PUBLISHER STATEMENT}

This work is made available according to the conditions of the Creative Commons Attribution-NonCommercialNoDerivatives 4.0 International (CC BY-NC-ND 4.0) licence. Full details of this licence are available at: https://creativecommons.org/licenses/by-nc-nd/4.0/

\section{LICENCE}

CC BY-NC-ND 4.0

\section{REPOSITORY RECORD}

Thompson, Laura, and Rose McCabe. 2019. "'good' Communication in Schizophrenia: A Conversation Analytic Definition". figshare. https://hdl.handle.net/2134/19528. 


\section{Author accepted version}

\section{CHAPTER TWENTY TWO \\ ‘GOOD’ COMMUNICATION IN SCHIZOPHRENIA: A CONVERSATION ANALYTIC DEFINITION}

Dr Laura Thompson (Loughborough University), Professor Rose McCabe (University of Exeter Medical School, UK)

\section{Chapter contents}

1. Introduction

2. How should we define 'good' psychiatric communication

3. Psychiatrist questions and the therapeutic alliance

4. Moving beyond 'open' vs 'closed': a more sensitive question classification

5. Project overview

6. Data analysis

7. The corpus

8. Findings

9. 'So- prefaced' declarative questions: psychiatrists working closely with patients' talk

10. Making empathic inferences: So-prefaced declaratives as formulations of patients' talk

11. Psychiatrists' declarative questions, patient responses and sequence constraint

12. Summary

13. Discussion and clinical relevance 


\section{Introduction}

Schizophrenia is one of the most serious conditions psychiatrists are likely to encounter. Its complex psychopathology includes changes in thought and perception delusions and hallucinations. Along with personal distress, this detachment from ‘reality’ (psychosis) brings complexity to psychiatrists’ interviews with patients. Not least, at times, an ontological 'incompatibility’. The clinician must walk a ‘tightrope’: asking questions of appropriate depth and pace, while maintaining an attitude of nonconfrontation and non-collusion around psychotic symptoms (Turkington \& Siddle, 1998). Meanwhile, the heterogenous course and clinical presentation of schizophrenia (Van Os \& Kapur, 2009) creates a second delicate balance to achieve. The psychiatrist must understand the individual in their unique psychosocial context: diagnostically disentangling 'pathological' behaviour from what may be valid attempts to deal with distress or disturbances caused by particular social circumstances (See BPS, 2014). Achieving this means putting patient experience at the heart of psychiatric communication - a partnership paradigm of care (NICE, 2009), removed from psychiatry's historic reputation of social repression.

The stakes involved are high. Psychotic symptoms are associated with increased risk of suicide (Palmer, Pankratz \& Bostwick, 2005) and rehospitalisation, incurring substansial clinical burden. Given the ultimate goals of consultations are the ameolration of symptoms and prevention of relapse, empirical models of 'good' communication are of economic value. Paradoxically, they are underdeveloped. Recent work attends seriously to the role of communication in improving the therapeutic value of clinician-patient relationships (Priebe et al., 2011) and, in turn, even multifactorial outcomes such as treatment adherence (Thompson \& McCabe, 
2012). Nonetheless, 'partnership’ constructs deemed essential for service delivery 'shared decision making' and 'patient-centredness' - remain elusive (Epstein 2005). These are, in the main, abstract ideals, not specific techniques conducive to clinician training.

\section{How should we define 'good' psychiatric communication?}

Conceptualising 'good' communication begins with identification of specific practices and how they advance the values of patients and the therapeutic relationship, or 'alliance' (Thompson et al., 2012). Alliance (a subjectively rated psychological construct) and communication (components of the behavioural exchange, with the capacity for objective analysis) are interrelated, but analytically distinct concepts (Priebe \& McCabe, 2006). Starting with the latter 'micro-level' would allow identification of tangible practices from which to explore their relationship with 'higher-level' subjective constructs or behavioural outcomes: treatment adherence. By identifying the systematic practices through which people perform and recognise social action in talk, the method of conversation analysis (CA) shows promise in understanding psychiatric communication at this level (Bergmann, 1992, McCabe, Leuder \& Antaki, 2009, McCabe, Heath, Burns \& Priebe, 2002). CA researchers use video and audio recordings of naturally occurring psychiatric interaction, and a detailed method of transcription to capture the minutiae of speech and elements of non-verbal behaviour. These provide analytical tools for exposing the underlying structures, or 'rules', that govern how activities are composed and organised. The results are highly descriptive, allowing exploration of topics as dynamic as the tacit skills by which delusional talk is recognised by psychiatrists (Palmer 2000). 
Health research, however, is driven by a motivation to link social phenomena to specific outcome metrics, enabling quality ‘standards' of care (NICE, 2014). This brings a poignant challenge. Is it possible to establish findings with applied value: to reconcile the nuances of psychiatric communication, like those elicited through detailed CA analyses, with more global outcome measures? To explore this question, we take the most fundamental practice in psychiatry as a case study: psychiatrists' questions.

\section{Psychiatrist questions and the therapeutic alliance}

Questions are the primary method for developing therapeutic goals, assessing symptoms and deducing diagnostic hypotheses. Their implications for the social relationship between doctors and patients should not be underestimated. As Heritage (2010) explains, if clinicians use neutral ‘social survey’ questions, they convey a stance of objectivised indifference towards the patients' response, cumulatively instantiating a bureacratic or 'anonymous' relationship. Effective clinicians tailor their questions to that particular individual i.e. 'recipient design', instantiating 'a caring relationship with patients’ (Heritage, 2010).

Conversation analysis is congruent with work on the constitutive view of relationships. Rather than treating facets of social relationships as 'independent variables with discursive consequences’ (Hopper \& Chen, 1996:310), the constitutive view construes them as constituted and reconstituted, on a turn by turn basis, by practices of social action that are co-constructed by speakers (Mandelbaum, 2003). Communicative practices, like questions, are therefore, not 'inherently neutral in terms of their implications for social and personal relationships' (Robinson, 
2006:154). CA findings increasingly reveal important ways in which talk may propose or construct particular relational alignments between participants (e.g. Robinson, 2006, Heritage \& Sefi, 1992). Unexplored however, is how, or if, questioning relates to the subjective psychological construct of 'relationship' - how one participant feels about another. The capacity to link communication practices to psychological measures of the psychiatrist-patient alliance in schizoprenia is not only of theoretical interest, but clinical value. Subjective ratings of the alliance are associated with improved treatment adherence in psychiatry (Thompson et al., 2012). Moreover, it would faciltate evidence-based interviewing techniques, enhancing the advice currently available for clinicians.

Clinical texts offer variable definitions of 'good' psychiatric questioning, bar one frequently overarching message: 'In general try to use open questions rather than leading questions or closed questions' (Burton, 2010), particularly at the start of the interview. This (quite crudely) categorises questions in binary terms on the assumption that 'open' questions align with ideals of patient-centredness, allowing patients to present themselves more freely in their psychosocial context:

Conducting an interview hastily and indifferently with closed-ended queries often prevents patients from revealing relevant information. Tracing the history of the presenting illness with open-ended questions, so that patients can tell their story in their own words, takes a similar amount of time and enables patients to describe associated social circumstances and reveal emotional reactions. (Routine psychiatric assessment, the merck manual, 2012)

However, crucially, 'open’ and 'closed' categories encompass numerous different subtypes, each of which may have different interactional consequences (Heritage, 2010) and index alternative social between the doctor and patient (Raymond, 2010). 


\section{Moving beyond 'open' vs 'closed': a more sensitive question classification}

Question taxonomies that move beyond an 'open' vs ‘closed' conceptualisation vary according to the accepted meaning of a question itself, i.e. whether constituting a type of sentence (interrogative), the speech act of requesting information (interrogative act) or 'the 'thing' which is being asked, and which, as a consequence, may be (partially) answered' (Groenendijk \& Stokhof, 1997). These definitions result in contrasting approaches to question classification, broadly (but not exhaustively) speaking; syntactically (by form), semantically (by meaning), pragmatically (by function). Independently, each of these classification types can only hope to identify a subset of the turns used for 'doing questioning' in clinical dialogue. Using a combination of these methods of classification - concepts derived from linguistics and CA - to sensitively code naturalistic interaction, Thompson et al. (2015) developed a handcoding protocol to identify and classify psychiatrists' questions in 134 outpatient consultation transcripts. Ten possible question subtypes were distinguishable, but they found psychiatrists used a subset (4/10) of question types regularly:

1) Yes/no auxiliary verb questions: a subtype of 'closed' question, syntactically identifiable with an auxiliary verb in the first position of the sentence, followed by the subject. e.g. Do you go to a day centre?

2) Wh questions: 'open’ questions that elicit information on a state of affairs or the property of an event, containing a question word in the first position e.g. who, what, when, why or how. e.g. how have you been feeling? 
3) Declarative questions: a subtype of 'closed' question with the syntax of a declarative sentence. e.g. so you feel a bit anxious? Recognition of declaratives as ‘questions' (i.e. requiring confirmation/disconfirmation) depends on sequential, prosodic and epistemic features, not syntax alone (Stivers \& Rossano, 2010, Buen, 1990, Heritage, 2012, Gunlogson, 2002). Declarative sentences with final rising 'questioning' intonation, denoted by '?' in transcripts were included, or coders looked to the next turn (the patient response) to see if it had indeed been understood as a question.

4) Tag questions: a subtype of 'closed' question that transforms a declarative statement or imperative into a question by adding an interrogative fragment (the 'tag') i.e. an auxiliary verb followed by a pronoun e.g. "isn't it?”

Associations with measures of patient adherence and the therapeutic alliance (Priebe \& Gruyters 1993) were examined, adjusting for patient symptoms, psychiatrist ID and amount of speech. Counter-intuitively, only declarative (closed) questions predicted better adherence and perceptions of the therapeutic relationship. Conversely, wh (open) questions predicted poorer perceptions of the therapeutic relationship and were also associated with increased positive symptoms, such as delusions and paranoia. It is unclear why this should be the case. Furthermore, from a conversation analytic perspective:

"Even where an utterance is in the linguistic form of a question, and seems to be doing questioning, the latter will not be adequately accounted for by the former. For if the question form can be used for actions other than questioning, and questioning can be accomplished by linguistic forms other than questions, then a relevant problem can be posed not only about how a question does something other 
than questioning, but about how it does questioning; not only about how questioning is done by non-question.” (Schegloff 1984 p34-35)

As Schegloff (1984) explains, identifying questions in dialogue is not a trivial matter.

What unites questions is their placement in conversation sequences - their form is not always synonymous with their social action (See also Stivers 2010). Declarative questions may be accomplishing more/other actions than questioning itself. Identifying these actions may provide explanatory and pragmatic insights into this outcome-based research, aiding application in practice.

\section{Project overview}

Building on Thompson et al. (2015), this study explores how language 'as action' can illuminate discursive practices embedded within psychiatry and help define 'good' communication in schizophrenia by an alternative - bottom up - approach. Using pychiatrists questions as a case study, the chapter contextualises statistical associations with the therapeutic alliance and treatment adherence and subverts more abstract, but widely held, views about how psychiatrists ‘should' communicate.

\section{Data analysis}

A random subset of 30 consultations from Thompson et al., (2015) was selected for analysis. Transcripts with mean frequencies below 3 declarative questions per 1000 words (31 consultations) were excluded to ensure a sufficient density of questions. Approximately 7 declarative questions from each consultation were extracted, providing a total of 210 for initial, exploratory, analysis. The study was informed by the methodology of conversation analysis (CA). The questions and surrounding talk were transcribed using Jeffersonian orthography (Jefferson, 1983), capturing microlevel features of interaction. Question extracts were analysed inductively for recurrent 
systematic, linguistic and sequential features - and on the understanding that to talk is always to 'do' something (Schegloff, 1996). On the basis of analytic descriptions from a turn-by-turn consideration of a single case, more general observations were gradually formulated as additional cases were examined - continually revising the summary of an apparent pattern to accommodate these instances (Ten Have, 1996).

\section{The corpus}

Data was drawn from an MRC study examining clinical interaction in psychosis (McCabe et al., 2013). 36 psychiatrists from outpatient and assertive outreach clinics across 3 centres (one urban, one semi-urban and one rural) were randomly selected. Written informed consent was obtained from 134 patients who met Diagnostic and Statistical Manual - IV (APA 2000) criteria for schizophrenia or schizoaffective disorder, following which their consultations were audio-visually recorded. Verbal dialogue was transcribed verbatim.

\section{Findings}

The functions of declaratives are more nuanced than their, sometimes negatively connotated ${ }_{2}$ label of 'closed questions' implies. Several features will be observed throughout the ensuing analysis. These show psychiatrists' declarative questions have the capacity to:

- Support attentiveness to client stances: showing the psychiatrist working closely with the patients talk.

- Display and confirm understandings of patient experience (hearably retaining an empathic function).

- Distil summmaries within a psychiatric frame of relevance. 
- Effectuate topical closure and change, offering a narrative sequencing function.

\section{A crucial distinction: declaratives compared to other 'closed' questions}

A declarative question ${ }^{1}$ not only projects the relevance of a yes/no type action, but can be differentiated from other 'closed' questions in important respects. In the psychiatric domain, epistemic stance is particularly relevant. Epistemic stance refers to the degree to which the psychiatrist conveys access to (i.e. is 'knowing' of) the information the question aims to solicit. Taking a simplified example from the present corpus, we can see there are various ways the same question could have been designed as a yes/no type initiating action - each to elicit the same information, yet a establishing a different 'epistemic gradient' (Heritage, 2010) between the psychiatrist and the patient:

Q 1) Do you feel a bit anxious? (Y/N interrogative)

Q 2) You feel a bit anxious, don't you? (tag question)

$\mathrm{Q}$ 3) You feel a bit anxious? (declarative question)

All of these questions refers to whether the recipient 'feels a bit anxious' - 'B-event information'(Labov, et al. 1977), only properly known by the patient who has epistemic primacy. However, each question represents distinct stances towards the information, as displayed in Figure 1, adapted from Heritage (2010). 
Figure 1. Psychiatrist question designs and epistemic gradients

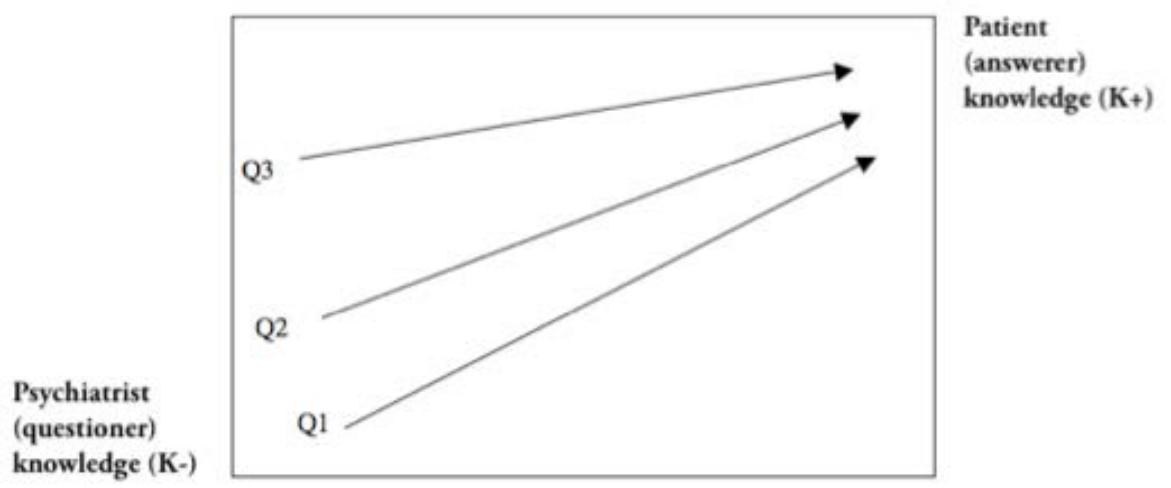

Q1 indicates that the psychiatrist has no certain knowledge of the patient feeling anxious, indexing a steep 'epistemic gradient' (see Figure 1) between the knowledgable $(\mathrm{K}+)$ patient and a relatively 'unknowing'_(K-) psychiatrist. Contrastingly, Q2 indicates a shallower gradient by displaying an inclination towards the likelihood that the patient does feel a bit anxious. While the psychiatrist formulates the utterances initially as a declarative statement 'you feel a bit anxious', his epistemic entitlement is ‘downgraded with a tag question’ (Heritage, 2012): ‘don’t you?', seeking confirmation of the assertion made in the declarative component.

Finally Q3, a declarative question, without an interrogative fragment (Q2) or auxiliary-subject preface (Q1), proposes a strong allegiance to the idea that the patient does indeed feel anxious. As Heritage (2010) posits, the latter declarative form 'merely seeks to reconfirm or alternatively convey inferences, assumptions or other kinds of 'best guesses”' (p9). Accordingly, Raymond (2010) argues, 'speakers assert 
the matters formulated in their initiating action and thereby claim to know about them (or assume them or treat them as established) as a basis for making confirmation of them relevant' (p92). While Q1, 2 and 3 are all versions of 'closed' questions that aim to solicit the same information from the patient, the selection of one form over another can invoke contrastive social relations between speakers and have significant consequences for the ensuing interaction (for an example in health interaction, see Raymond 2010). Taking the 'unknowing' stance of a $y / n$ interrogative 'can invite elaboration and sequence expansion, while the 'knowing' $y / n$ declarative form merely invites confirmation of known information by the recipient, who is projected as an authoritative source' (Hertitage, 2010 p10). Having identified interactional distinctions relative to other 'closed' questions, some core observations of declaratives in this dataset are next reported.

\section{'So- prefaced' declarative questions: psychiatrists working closely with patients' talk}

A fundamental assumption in CA is that, in constructing a turn at talk, speakers usually address themselves to preceding talk and, most commonly, the immediately preceding talk (Sacks 1987, 1992; Schegloff and Sacks, 1973). On initial examination

of the 210 declarative questions, two distinctions were observable in this respect (as initially summarised in Thompson et al., 2015). A minority appeared in a 'checklist' (Heritage, 2010) form - truncated questions that represent rapid topic shifts following a patient answer to a prior question (16) e.g 'Sleeping okay?', 'good appetite?'. A slightly larger proportion (23) incorporated patients’ immedietly prior talk, repeating lexical elements verbatim (See Robinson, 2013, Robinson \& Kevoe-Feldman, 2010).

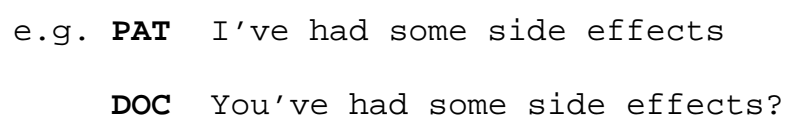

Formatted: Font: Not Bold, Complex Script Font: Times New Roman, 11 pt, English (U.K.), Do not check spelling or grammar

Formatted: Font: Not Bold, Complex Script Font: Times New Roman, English (U.K.), Do not check spelling or grammar 
The majority of questions displayed a further level of abstraction - as per Heritage's (2010) assertion - conveying 'inferences or assumptions’ about the patients’ prior talk (171). Further examination showed that nearly half of these cases were 'so-prefaced' inferences (90). Similar practices have been shown to have analytical salience in contexts outside of psychiatry (Johnson \& Cotterill, 2002, Beach \& Dixon, 2001) and ‘so’ particles have been found to affects a question’s function (Bolden, 2006). Table 1 displays a collection of examples from the dataset (Thompson et al., 2015). Two basic observations will be drawn from these examples and their sequential environments, Formatted: Font: Not Bold, Complex Script Font: Times New Roman, 11 pt,
English (U.K.), Do not check spelling or grammar

features analysed in more depth as the analysis proceeds. The cases shown here were selected as particularly clear examples of the systematic properties observed.

Table. 1 A collection of so-prefaced declaratives

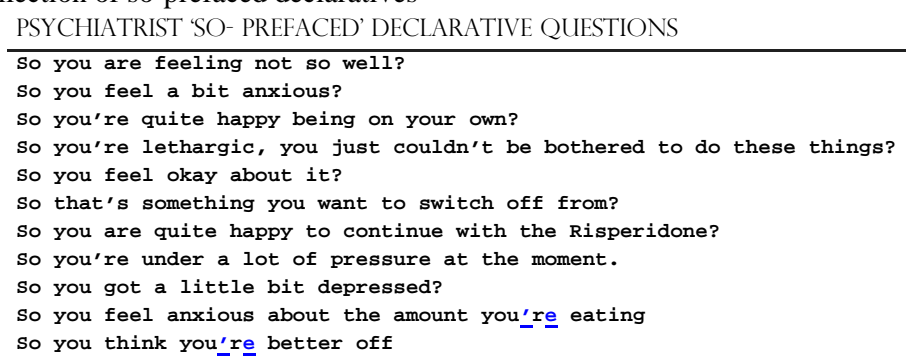

1) The declarative questions presented in extract 1 are all prefaced by 'so'. This discourse marker constitutes one way of indexing 'inferential or causal connections' (Bolden 2009:974) with prior talk (For alternative pragmatic functions of so, see Bolden 2009). As such, in each case, the psychiatrist frames the ensuing declarative question as closely resulting from, thereby contingent upon, the patients' prior talk (See Bolden, 2009, Schiffren, 1987). Bolden (2006) found 'so' is overwhelmingly involved in 'doing other-attentiveness' in interaction. Indeed, what invariably followed was not only a declarative, but a display of understanding of that talk: each of the declaratives in extract 1 constitutes a 'formulation' (Heritage \& Watson, 1979). 
The psychiatrist appeared to present a summary of these utterances, replacing the patients' wording with their own formulation that captures the 'gist' (Heritage et al., 1979) of the patients' turns. This was frequently within a psychiatric frame of relevance (cf Beach et al., 2001, Depperman \& Fogasy, 2011). As evident in Table 1, 4 of the questions refer to the how the patients' 'feels' and all contain reference to some kind of emotional state. The psychiatrist was observed producing a psychological upshot of events that the patient describes (an account or troubles telling), but while presented as something implicit within the patients’ prior talk, this process involved editing, deleting and, to some extent transforming (Heritage et al, 1979) the patient's contribution, consistent with current research on formulations in psychotherapy.

2) Psychiatrists' use of declarative questions had significant interactional consequences. Each of the examples in Table 1 contain 'B-event information' (the patient's psychological state) characterised by the 'known in common' (Heritage, 2012) epistemic authority of the patient (which can preside over rising 'questioning' intonation in terms of the interpretation of a declarative as 'doing questioning'). The psychiatrist therefore creates a slot for the patient to (dis)confirm. The (dis)confirming action made relevant is minimal relative to other yes/no type initating actions with less shallow epistemic gradients. By providing a resource to ostensibly display a summary of understanding, declaratives may be one tool psychiatrists can use in sensitively closing down particular trajectories of talk and managing topic transition. Indeed, Johnson \& Cotterill (2002) documents the use of 'so' for prefacing questions that function as 'topic sequencers.' The constraining effect on sequence expansion here was evident in 4 ways; 1) Patient responses were confirming/disconfirming tokens rather than narratives 2) Psychiatrists' did not expand beyond the base 
declarative - answer sequence: third position talk was absent or merely a 'sequenceclosing third' (Schegloff, 2007) e.g. an assessment like 'good' 3) This was followed by a topic or activity shift. 4) Greater use of declarative questions was associated with less patient talk overall in consultations. As such, psychiatrists' so-prefaced declaratives appeared one resource for closing down patients' narratives/troubles tellings - in a manner that simultaneously displayed intersubjectivity - and managing the interactional progress of the interaction.

These two features are evident in Extract 1:

\section{Extract 1}

1 PAT: >I $\uparrow$ mean< $\uparrow$ it's (.) it's $\uparrow \uparrow$ eight months on and I can still remember it.

DOC: ${ }^{\circ} \mathrm{Mm}::^{\circ}$

4 PAT: The $\uparrow$ last thing I wa:nt is for somebody to keep re个minding me.

6 Doc: 'Oka: : $y^{\circ}$ so $\uparrow y o u$ you think you're better off

7 PAT: Yes.

8 DOC: Just looking forward.

9 PAT: Yes.

10 DoC: ${ }^{\circ 0}$ Okay. ${ }^{\circ}$

$11 \quad(5.6)$ ((Doctor writes in notes)

12 Doc: .hhh did you get the $\uparrow$ job you've $\uparrow$ been (.) applying

$13 \quad \uparrow$ for?

14 PAT: Yes I got the job.

(DOC $=$ psychiatrist $\mathrm{PAT}=$ patient $)$ 
In line 06, the psychiatrist formulates what the patient has said regarding his reluctance to receive counselling for distressing (past) psychotic experiences. He replaces the patient's description with his own psychological summary 'so you you think you're better off?', bringing the discussion to a close. The question appears to merely recapitulate and display understanding of the patient's words: the 'so' preface indicates the patient should understand the upcoming action as a natural upshot. As Fraser (1999) suggests, discourse markers (such as 'so' in question prefaces) can 'signal a relationship between the segment they introduce....and the prior segment' (p50). However, the brevity of this turn relative to the patient's (spanning lines 01-05) indicates that, in the process of formulating, the psychiatrist has deleted parts of his account i.e. eight months on/his disinclination to be reminded etc. Moreover, given the patient's prior action was hearable as a complaint - recalling the enduring and undesirable nature of his memories - through editing of its design and terminology an element of transformation has occurred (Heritage et al., 1979). The psychiatrist recasts the patient's answer to accord with a more positively framed outlook i.e. that he thinks he is 'better off' (without counselling).

Turning to the sequential aspects of the question - the patient's thoughts constitute 'Bevent information' (Labov, et al. 1977), mutually conceivable as the patient's epistemic domain. A relevant slot is therefore created for the patient to confirm/disconfirm. While he provides this in line 07 , the psychiatrist increments his question: 'just looking forward' in line 08. By recompleting his question, he sequentially deletes the patient's answer: renewing its relevance in line 09. Notice that the declarative question was originally produced with a turn-initial 'okay'. These 
actions can be used as 'pre-closing' devices (Beach, 1993, 1995) deployed to acknowledge, yet enforce closure on immediately prior elaborations (Beach et al., 2001). Indeed, following this confirmation in line 09, produced with terminal intonation, the psychiatrist hearably orients to topical closure. He does not expand the sequence in the third position (Schegloff, 2007) by projecting further related talk, rather deploys the receipt token 'okay' - which can be used to mark an upcoming change of activity (Gardner, 2001). Accordingly, a change is forthcoming: following a pause in which the psychiatrist writes in his notes, we see a marked shift in topic in line 12 - the psychiatrist inquires about the patient's prospective job application.

\section{Making empathic inferences: So-prefaced declaratives as formulations of patients' talk}

In extract 1, the psychiatrist produced a formulation of the patient's prior turns at talk.

Garfinkel and Sacks (1970) first defined this interactional phenomena:

'a member may treat some part of the conversation as an occasion to describe that conversation, to explain it, or characterise it or explicate, or translate, or summarise or furnish the gist of it.....that is to say, a member may use some part of the conversation as an occasion to formulate the conversation'. (p350)

Formulations have been a prominent theme in conversation analytic research on psychotherapy. Through this resource, speakers can offer their interpretations (Drew, 2003), candidate understandings (Schegloff, 1996) or candidate representations (Hutchby, 2005) of previous talk by their interlocuter. This line of inquiry was initially developed in two seminal papers by Heritage and Watson $(1979,1980)$, in which they characterised some systematic properties of formulations. Here, the focus is on a central aspect, readily detectable in the present dataset;

'Displays of understanding can be achieved by producing a transformation or paraphrase of some prior utterance. Such paraphrases preserve relevant features of a prior utterance while also recasting them. They thus manifest 
three central properties: preservation, deletion and transformation' (1979 p129).

Extracts 2, 3 and 4 demonstrate how such a pattern was manifest in this corpus of soprefaced declarative questions. In each extract, the psychiatrist formulates the patients' account, replacing it with their own version of the patients' words. Specifically, a summary that displays sensitivity to the psychological implications of the events described (cf Johnson, 2002, Beach et al., 2001). In doing so, the psychiatrist edits and deletes parts of the patients' prior utterances, transforming the report within a 'psychiatric' frame of relevance. These declaratives thereby repeatedly display the 'fitting of differently focused, but related talk to some last utterance in the topic’s development' (Schegloff et al., 1973:305). Extract 2 (Thompson et al., 2015) below displays this in relation to how the patient feels about spending time by himself.

\section{Extract 2}

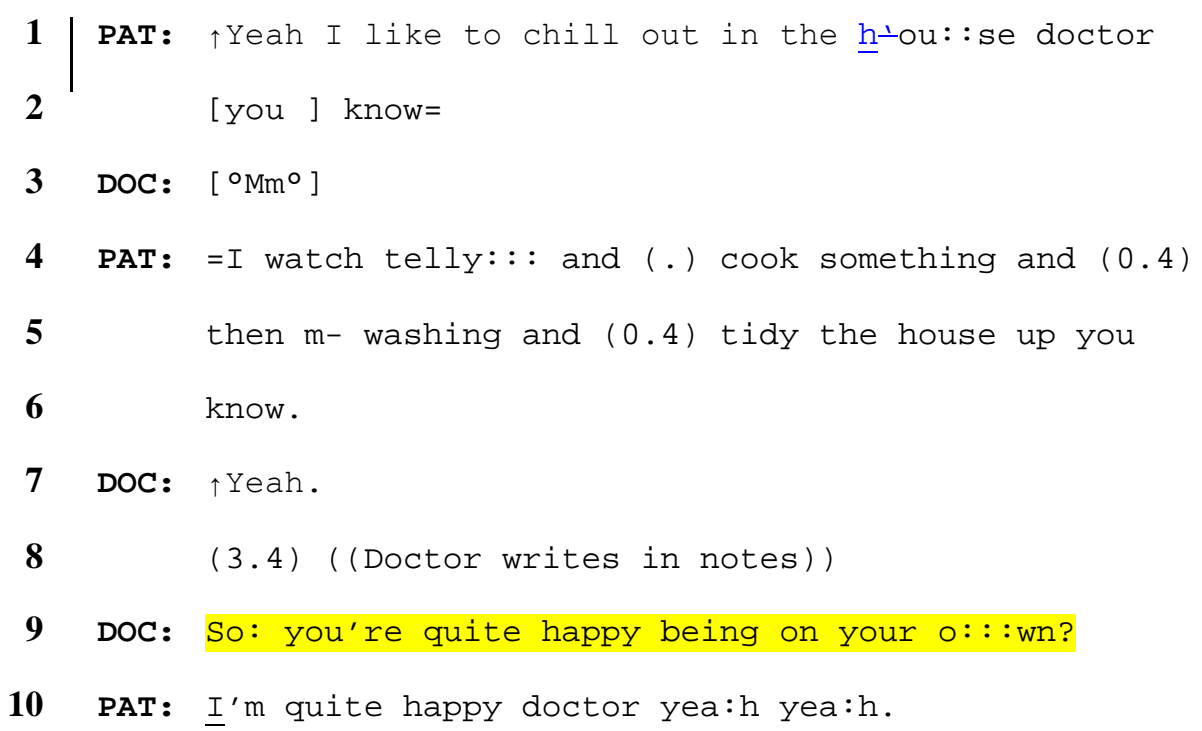


In line 09 the psychiatrist deploys a so-prefaced declarative to condense a larger stretch of the topical talk in which the patient describes his daily homelife - activities engaged in when not spending time with his friends. The psychiatrist offers a formulation of the patient's experience 'so you're quite happy being on your own'. This provides the opportunity to intersubjectively ground (Clark \& Schaefer, 1989) the doctor's conclusion by establishing the conditional relevance (Schegloff, 1972) for a confirmation from the patient - which he provides in line 10. The psychiatrist's formulation is presented as a mere summary - 'you're quite happy being on your own' being ‘something implicitly meant by the client' (Bercelli, 2008). However, in the process of its production, the psychiatrist has the opportunity to discard irrelevant material, here the information of mundane activities (watching television, cooking and tidying etc) and shape that which remains in a more 'overall' emotional framework that the patient is 'happy being on his own'.

Antaki (2008) asserts such displays of understanding in psychotherapy show 'ostensible cooperation': they appear to be replaying a summarised version of the patient's prior utterances, but in doing so have 'deleted some material, selected what suits the interests at hand, and edited is design and terminology' (p30). This is also observable in extract 3 below.

\section{Extract 3}

1 PAT: Yeah quite bad yeah.

$2 \quad($.

3 PAT: I don't like going anywhere on my own really and

4 that now .hhh my mum's been taking me a lot of

5 pla:ces and that. 
7 PAT: In the car.

9 PAT: $\cos$ I get paranoid when I'm on the bus and everything and I think other people are after me an' that.

12 $(0.6)$

13 Doc: .hhh so you are feeling $(0.4)$ not so well?

14 PAT: No: : :

Unlike extract 2, the patients' narrative that precedes the psychiatrist's question (line 09) is hearable as a troubles telling. The patient claims his paranoid thoughts of late (the topic of a prior line of questioning) have been 'quite bad', proceeding to provide evidential grounds for this assessment in lines 01-09 - a reliance on his mum to take him places and feeling paranoid when on the bus. The psychiatrist passes up the opportunity to receipt or respond in lines 02,06 and 08 - the latter silence follows an increment 'in the car' that Schegloff (2000) noted, when initiated post-gap, can be seen to address 'the absence so far of ensuing talk' in pursuit of a response. This occasions the patient's continuation in line 09 'cos I get paranoid....' that serves to account for his disinclination to go out and his dependence on his mother by reference to a delusion.

Like the prior examples, in line 13 the psychiatrist formulates what the patient has said. While he displays a candidate understanding and evaluation 'so you are feeling not so well', he simultaneously distils, and thereby deletes, the relatively extensive material provided by the patient into an overall general sense or 'gist' (Heritage et al., 
1979) of the patient's wellbeing. By summarising the patient's description in a general framework, this enables the psychiatrist to 'label' (Johnson, 2002:105) the patient's narrative - in so far as how the patient is 'feeling' overall - and reduces the individual significance (thereby need to address) of specific elements of the patient's account. This may be particularly pertinent when discussing delusions, like those the patient concedes to in lines 09 and 10. By displaying, and inviting confirmation of, how the patient may 'feel' on account of his description, it may allow the psychiatrist to be sensitive to the implications of the experience, while maintaining a clinically desirable attitude of non-collusion with aspects of its content e.g. here that 'people are after' the patient. Moreover, this arguably makes transition onto the next activity (including possible resolution of the problem), an easier subsequent interactional move. A similar orientation is evident in extract 4 (Thompson et al., 2015).

\section{Extract 4}

1 PAT: E:::::r, $i$ :t's just that $(0.4)$ someti:me in the afternoon I get $(0.6)$ like, (.) you know I get the feeling that $($.$) i:t's (0.6)$ going to happen to me: :

4 (.)

5 PAT: I will end up in the hospital.

7 Doc: Okay.

8 PAT: A: : : nd er

9 Doc: So you feel a bit anxious?

10 PAT: Um yea: : :h

Here, the patient's narrative, also hearable as a troubles telling, asserts concern regarding his recent mood, concern of relapse and associated return to hospital. The 
psychiatrist receipts the account in line 07 'okay' and, while the patient produces an incomplete turn constructional unit (TCU) in line 08 'and er', the psychiatrist takes the next turn as an opportunity to formulate the talk so far. Indexing the inferential connection between the prior talk and his upcoming action with a recognisable 'so' preface, he invites confirmation of his understanding of the emotional upshot of the patient's account 'you feel a bit anxious'. In doing so, he preserves the 'feeling' the patient describes in line 03, whilst simultaneously deleting the finer details of the account surrounding its circumstance e.g. that the patient will end up in hospital, the feeling occurs in the afternoon.

At the same time, an element of transformation occurs: the psychiatrist specifies the 'feeling that it is going to happen to me (.) I will end up in hospital' as feeling a 'bit anxious' (line 09), thereby recasting the information in more recognisably 'psychiatric' terminology. In this way the psychiatrist, as in extract 3 , is able to evaluate, summarise and label the patient's more extensive talk. This provides the opportunity to intersubjectively ground the psychiatrist's understanding of patient's topical talk, but may also assist in transforming the account according to 'institutional relevancies' (Depperman et al., 2011:117). The psychiatrist’s (institutional) tasks may be supported by a device that allows for selective formulation of the relevant outcomes of patient's answers. We can see evidence of this in extracts 5 and 6.

\section{Extract 5}

1 Doc: So on the whole from a psychiatric point of view (.)

2 you're very stable,

3 PAT: Yes for the mome: :nt.

\section{Extract 6}


DOC: So I think in terms of $\uparrow$ what we're doing at the moment

3 PAT: $\uparrow$ Yes $\uparrow$ yes.

The psychiatrist produces, and attempts to solicit agreement, of an upshot by first qualifying that the formulations, in which the patient is the central figure (you're/you), are not verbatim, but a consequence of the sense the psychiatrist has made of the patients' prior talk. Specifically, 'in terms of what we're doing at the moment' (extract 6 line 01) i.e. 'from a psychiatric point of view' (extract 5 line 01). As such, the psychiatrist narrows the frame of relevance for the formulation that follows: extract 5, 'you're very stable', and extract 6, 'you're quite satisfied', are presented as contingent on these terms of reference, the emphasis being psychiatric interpretation - a summary of wellbeing using the medical terminology ('stable’) and overall patient satisfaction with treatment. In doing so, the psychiatrist asserts justification for the editing and deleting of the patients' prior talk by explicitly formulating that the communication and its frame of relevance is being shaped by the activities and setting (See Drew, 2003) in which they are engaged.

While, as Heritage and Watson (1979) explain 'the uses of formulations are multiplex...they may be used to address an immense variety of matters, these matters being, in their most specific terms, heavily embedded in the specific stretches of talk in which they occur' (p128), there may be particulars to formulations that make them a conducive resource for institutional encounters (Drew 2003) such as those in psychiatry. For Antaki (2008), the 'common thread' of formulations is that the institutional agent 'plucks' out something in the other's words and, while presenting it 
as a mere neutral summary or implication, uses the opportunity to edit it in ways that will help the speaker's own institutional interests. As one resource psychiatrists can use to produce 'psychiatric summaries' of preceding talk, declarative questions may further be suited to the closing down and managing of topical trajectories.

\section{Psychiatrists' declarative questions, patient responses and sequence constraint}

A consistent theme in CA research on declarative questions and formulations is that of sequence constraint: both in terms of expanse of the second pair part (dis)confirmation or third position post-expansion by clinicians (i.e. talk by a first speaker that deals with a second position response (Schegloff, 2007)). In a study including formulations in psychotherapy setting, Bercelli (2008) noted clients' confirming responses generally consist of a minimal token (such as yes or hm, with falling intonation) and are not post-expanded, or only minimally post-expanded by therapists. Beach et al. (2001) examined how formulations were used to organise patients' talk by closing down narratives/troubles tellings - the formulations (declaratives) initiated a three-part cycle 1) interviewers' formulated understandings 2) patients' confirmations 3) topic shift by the interviewer - accordant with extract 2.

Raymond (2010), compared the sequence constraining effect of declaratives, compared to that of yes/no interrogatives: 'The different actions made relevant by yes/no declaratives and yes/no interrogatives are reflected in the forms that responses to them typically take and in the ways that sequences initiated by them come to be expanded or not’ (p95). Yes/no declaratives effectively constrain sequence expansion: the constraints set in motion by this question type (that assert the matter as 'known') can be satisfied by mere confirmation, typically involving no third position expansions, or minimal sequence-closing thirds (Schegloff 2007) e.g. assessments. 
Table 2 displays the distribution of patient responses and third position talk (beyond that of a sequence-closing third) from the psychiatrist. We can see that declarative formulations were designed largely with positive polarity, preferring 'confirming responses', consistent with Heritage and Watson's (1979) observation of the 'sequential power' of formulations - their projection of agreement - that patients have to actively provide, as in extract 6 , or combat in the next turn as in extract 7.

\section{Extract 7}

01 DOC: SO YOU'RE FEELING better in any case.

02 PAT: Well I feel a lot better than I did two weeks ago two

03 or three weeks ago $\uparrow e:: r$

The patient resists the terms of the question, specifying that he feels better than he did 'two weeks ago', thus narrowing the scope of what he is confirming with additional elaboration. 'Non-conforming' i.e. narrative responses, like we see here, are the most frequent sequence-specific method for managing misalignment between speakers regarding the particular choice posed by a y/n question (Raymond, 2006).

Table 2. Responses to so-prefaced declaratives and third position psychiatrist expansion

\begin{tabular}{lccc}
\hline & $\begin{array}{c}\text { (Dis)Confirming } \\
\text { response }\end{array}$ & Narrative & $\begin{array}{c}\text { Third position } \\
\text { expansion by } \\
\text { psychiatrist }\end{array}$ \\
\hline All questions & 49 & 19 & 11 \\
Positive questions & 41 & 14 & 9 \\
$\begin{array}{l}\text { Negative } \\
\text { questions }\end{array}$ & 8 & 5 & 2 \\
\hline
\end{tabular}

As can be seen in Table 2, only 19 patients within the corpus resisted the constraints of the question by producing a non-conforming narrative response (See Raymond, 2006). The majority produced confirming responses (e.g yeah, mm) consistent with 
the identified preference for type-conformity (Raymond, 2003). In terms of whether psychiatrist expansion past the minimal base declarative-confirmation sequence, in only 11 instances did psychiatrists produce a turn in the third position that projected additional talk. As we see in extract 8:

\section{Extract 8}

101 Doc: So yo-you're feeling a bit low at the moment?

202 PAT: Yeah.

3 03 Doc: Can you explain ho: :W,

In line 03 the psychiatrist projects further elaboration (an account to 'how' the patient feels low) as relevant by shifting to display a less 'knowing' (K-) stance. In the remaining cases, psychiatrists followed patient answers with a shift in activity, sometimes prefaced by the token 'okay' signalling this as upcoming, or brief assessments i.e. sequence - closing thirds (Schegloff, 2007).

\section{Is sequence constraint associated with amount of patient talk?}

Psychiatrists' declarative questions in this corpus were responsive to patients' prior utterances. They displayed sensitivity to, and understanding of, the psychological aspects of their accounts, drawing sequences to a close by regularly attracting (dis)confirming, rather than more lengthy 'misaligned', responses. This prompted the hypothesis that, using more ‘sequence closing' devices in consultations to manage the interactional progress of the session - and perhaps indexing greater mutual 'understanding' - may have a bearing on patients' contributions overall. Using Pearson's correlation to preliminarily explore this conjecture, the bivariate association between psychiatrists' declarative questions and amount of patient talk (words per consultation from verbatim transcripts) within each encounter was examined. 
Table 3. Correlation with amount of patient talk

\begin{tabular}{lll} 
& \multicolumn{2}{l}{ Psychiatrists' declarative questions } \\
\hline Patient words & $\mathbf{R}$ & $\mathbf{P}$ \\
& $-.219 *$ & .013 \\
\hline * Correlation is significant at the $\mathbf{p}<.05$ level
\end{tabular}

As can be seen in Table 3, there is a statistically significant negative correlation - the more declarative questions psychiatrists asked, the fewer words patients said in consultations.

\section{Summary}

Psychiatrists' use of declarative questions is associated with better perceptions of the therapeutic alliance and adherence in schizophrenia (Thompson et al., 2015). Indeed, examined qualitatively, these questions are more complex interactional objects than the conventional binary definition (open q's vs closed q's) implies. Declaratives were recurrently so-prefaced formulations of patients' prior talk. Through the shallow epistemic gradient they created between clinician and patient, and features of turn design, declaratives could be used to convey a distinct relationship to patients' prior utterances. Not least, so-prefacing framed the question as contingent on (and inferentially connected to) patients’ prior talk (narratives or troubles tellings) and psychiatrists' lexical choices displayed sensitivity to its emotional implications by making implicit psychological meanings explicit: often specifying how the patient must 'feel' on account of the events they described.

While displaying a degree of understanding and the opportunity for the patient to confirm the psychiatrists' summaries, the production of declaratives involved simultaneously deleting and editing the patients' contribution, so as to recast it in a more psychiatric frame of relevance. For example, 'thematising' the patient's answers 
within a general framework: an 'overall' emotional state, condition or sense of wellbeing. A resource to ostensibly display a summary of understanding, declaratives also constitute one tool psychiatrists can use in sensitively closing down particular trajectories of talk and managing topic transition. The constraining effect on sequence expansion in relation to patients' prior talk was evident in 4 ways; the minimal responses made relevant by declaratives; absence of third position post-expansion from psychiatrists; subsequent topic/activity shift; and correlation between more declaratives and less patient talk overall.

\section{Discussion and clinical relevance}

Questions are fundamental in managing the alliance between psychiatrists and patients with schizophrenia. Yet formal guidelines for questioning practices remain unspecified, beyond general advice discouraging overuse of 'closed questions' (Burton, 2010). Conversely, declarative formulations, one subtype of 'closed' question, offer a sensitive device for intersubjectively grounding and displaying understanding of patient's contributions while capturing psychiatrically relevant upshots - crucial for appropriate treatment decisions, conducive to adherence. Moreover, what would clinical interaction look like without these displays of understanding? By displaying a more 'knowing' stance than other question types, declaratives create an opportunity for patients to confirm psychiatrists' grasp of their state of affairs, such that they can function, and be hearable by as, displays of understanding (Depperman et al., 2011), active listening (Hutchby, 2005) and empathy (Ruusuvuori 2005, 2007), perhaps explaining their link with better therapeutic alliances. Indeed as Suchman’s (1997) definition states: 
Empathic communication entails the accurate understanding of the patient's feelings and the communication of that understanding back to the patient in such a way that he/she feels understood (Suchman et al, 1997)

Training clinicians to ask more declarative questions at appropriate points may be one method of improving the therapeutic alliance and subsequent adherence. Alternatively, declarative formulations may reflect psychiatrists' increased propensity to display empathic responses with engaged, adherent patients. Through this lens, declarative questions, represent one possible communicative index for how positive alliances and/or adherence are manifest in interaction i.e. 'a rich region of interaction in which to study the constitution of relationships and intersubjectivity' (Robinson 2006: 156). It may be easier for psychiatrists to achieve, display and invite confirmation of their 'understandings' with patients who are more adherent and engaged with treatment in the first place. Meanwhile patients who are 'understood' may need to misalign from the constraints of psychiatrists' questions, e.g. through narrative responses, much less - one possible explanation for why declaratives were associated with less patient talk overall. Relatedly, one would expect achieving mutual understanding might be more difficult in symptomatic patients e.g. those experiencing delusions. This could explain why wh-questions - 'open' questions that presuppose less understanding thereby inviting more extensive responses - were associated with symptoms and poorer psychiatrist alliance ratings in the earlier study (Thompson, et al. 2015).

Declaratives may also be a useful tool for clinicians on another practical level: aiding in distilling and recording psychiatric summaries and managing the interactional progress of the session. These questions are 'epistemically designed' to add little 'new to the sequence and thereby to effectuate a move toward closing the topic' (Heritage, 
2012:48). In doing so, they created relevant junctures at which psychiatrists could shift to the next topic of the next pending agenda item. As they can do this in 'responsive' and psychologically sensitive way, perhaps such actions 'detoxify topic shift, therefore minimizing the likelihood that movement forward in the interview can be framed as a doctor's heavy-handed pursuit of a medical 'agenda' removed from the patient's concerns' (Beach et al., 2001: 29). Formulations are a means to transform patients', often detailed and multifaceted, accounts according to psychiatric relevancies. In particular, sensitivity to the main emotional theme underpinning their descriptions was observed, thus conceptualising the situation talked about in a 'certain way’ (cf. Heritage et al., 1979; Drew, 2003; Antaki, 2008). The capacity of formulations to achieve this may offer pragmatic applications in the treatment of schizophrenia. Psychotic symptoms are often the source of interactional tension in psychiatric outpatient consultations (McCabe et al., 2002): it can be problematic to establish a shared understanding of two differing versions of 'reality'. Declarative formulations, when used to display candidate understandings of how the patient may 'feel' on account of these experiences, could be one resource to display sensitivity to, and establish a shared understanding of, the emotional implications while avoiding collusion or direct confrontation with the content of particulars of that account.

While the issue of quantification has been somewhat controversial in CA (e.g. Schegloff, 1993), these findings show promise in establishing which communication practices may be meaningful to outcomes like the therapeutic alliance and adherence. Combining qualitative and quantitative methods 'allows for the synergistic interaction between the two' (Epstein et al., 2005:1522). After inductive quantitative/coding analyses (ideally based on CA sensibilities (See Stivers 2015)) yields a phenomenon 
of interest, CA provides a contextualised case-by-case analysis to generate explanatory hypotheses, in a detailed and transparent manner that is not possibly with quantitative analyses alone. These hypotheses are theoretically strengthened as they are grounded in empirical observations. Specifically, conversation analytic results, that 'are descriptions of the organisation of conduct that investigators validate qualitatively by reference to the participants’ own actions in situ’ (Heritage et al., 2006: 365). Such findings would pave the way for training interventions to optimise therapeutic effects by explicitly orienting communication to accomplish intermediate outcomes e.g. empathic understanding, in service of improving the psychiatrist-patient alliance.

\section{Clinical practice highlights}

1. Binary definitions of 'good' questioning ('open' vs 'closed') in psychiatric texts books may be too crude for utility in practice.

2. The function of declaratives, a subtype of 'closed'_question, are more nuanced than this definition suggests - they offer clinicians a device to enhance their interactions, in ways aligned with 'patient-centred' ideals.

3. Using 'so prefaced' declarative questions may help clinicians display attentiveness to patient stances and accounts - explicitly showing that they are working closely and responsively with the patient's talk. This may be preferable to more 'checklist' approaches to psychiatric interviewing, associated with rapid topic change and minimal responses to each patient answer.

4. Using declaratives appropriately may help clinicians conduct topic transition sensitively and maintain the relevance of psychiatric goals e.g allowing clinicians to distil an overall impression of patients' mental state and wellbeing from patients previous (lengthier) accounts.

5. Clinicians can use declarative questions to display empathy by seeking confirmation of their understandings of patient experience and its emotional salience.

6. Declarative formulations may enable clinicians to engage with the emotional implications of psychotic experiences e.g. delusions, while avoiding confrontation or collusion with particulars of patients' accounts.

7. Making clinicians aware of declarative formulations and how they can be used in psychiatric interaction may be one a way of improving the therapeutic alliance and subsequent adherence to treatment.

\section{References}

American Psychiatric Association (APA) (2000) Diagnostic and statistical manual of mental disorders (4th ed., text rev.). Washington, DC 
Antaki, C. (2008) Formulations in psychotherapy. In A. Peräkylä, C. Antaki, S

Vehviläinen and I Leudar (eds.) Conversation Analysis of Psychotherapy, Cambridge.

England; CUP.

Beach, W. A., Dixon, C.N. (2001) Revealing moments: Formulating understandings of adverse experiences in a health appraisal interview. Social Science and Medicine, $52,25-44$

Bercelli, F. et al (2008) Clients’ responses to therapists’ reinterpretations. In A. Peräkylä, C. Antaki, S Vehviläinen and I Leudar (eds.) Conversation Analysis of Psychotherapy, Cambridge. England; CUP.

Bergmann, J.R. (1992) Veiled Morality: Notes on Discretion in Psychiatry. In P. Drew and J. Heritage (eds) Talk at Work pp. 137-162. Cambridge: Cambridge University Press

Bolden, G. (2006) Little words that matter: discourse markers 'so' and 'oh' and the doing of other-attentiveness in interaction. Journal of Communication, 56, 661-688

Bolden, G., (2009) Implementing incipient actions: the discourse marker 'so' in English conversation. Journal of Pragmatics, 45, 974-998

The British Psychological Society. (2014) Understanding Schizophrenia and Psychosis: A Report by the Division of Clinical Psychology. Retrieved from 
http://www.bps.org.uk/networks-and-communities/member-microsite/division-

clinical-psychology/understanding-psychosis-and-schizophrenia

Beach, W.A., (1993) Transitional regularities for 'casual' 'okay’ usages. Journal of

Pragmatics, 19, 325-352

Beach, W.A. (1995) Conversation analysis: “Okay” as a clue for understanding consequentiality. In S.J.Sigman (Ed.) (pp. 121-161). The consequentiality of communication, Hillsdale:Erlbaum

Buen, R.J. (1990) The Recognition of Declarative Questions in Informative Dialogues. Tilburg University Press

Burton, N., (2010) Psychiatry. Oxford: Wiley Blackwell

Clark, H. H., Shaefer, E.F. (1989) Contributing to discourse. Cognitive Science, 13, $259-294$

Depperman, A., Fogasy, S. (2011) Doctors’ questions as displays of understanding. Communication and Medicine, 8, 111-122

Drew, P. (2003) Comparative analysis of Talk in Interaction in Different Institutional Settings: A sketch. In Phillip Glenn, Curtis D. LeBaron and Jenny Mandelbaum. Studies in Language and Social Interaction: In Honor of Robert Hopper. Mahwah, New Jersey: Lawrence Erlbaum Associates Publishers 
Drew, P., Holt, E. (1998) Figures of speech: Figurative expressions and the management of topic transition in conversation. Language in Society, 27, 495-522.

Epstein, R.M., Franks, P., Fiscella, K., Cleveland, G.S., Meldrum, S.C., Kravitz, R.L.,

Duberstein, P.R. (2005) Measuring patient-centred communication in PatientPhysician consultations: Theoretical and practical issues. Social Science and Medicine, 61, 1516 - 1528

Fraser, B. (1999) ‘What are Discourse Markers?’ Journal of Pragmatics, 31, 931-52.

Gardner, R. (2001) When Listeners Talk: Response Tokens and Listener Stance. J Benjamins Publishers

Garfinkel, S., Sacks, H. (1970) On formal structures of practical actions. In J. C. McKinney and E.A. Tiryakian (eds) Theoretical Sociology. New York: AppletoonCentury-Crofts

Groenendijk, J., Stokhof, M. (1997) Questions. In van Benthem, J. and ter Meulen, A., (eds) Handbook of Logic and Language. Cambridge, MA: MIT Press: 1055-124

Gunlogson, C. (2002) Declarative Questions. In B. Jackson, (ed.) Proceedings of Semantics and Linguistic Theory XII, Ithaca, NY: CLC Publications. 
Heritage, J., Watson, R., (1979) Formulations as Conversational Objects in George

Psathas (ed) (pp. 123-162) Everyday Language, New York, Irvington Press.

Heritage, J., Watson, R. (1980) Aspects of the Properties of Formulations. Semiotica 30, 245- 262.

Heritage, J., Sefi, S. (1992) Dilemmas of advice: aspects of the delivery and reception of advice in interactions between health visitors and first time mothers. In P. Drew and J. Heritage (Eds) Talk at Work. Cambridge: Cambridge University Press

Heritage, J., Maynard, D.(2006) Problems and prospects in the study of doctor-patient interaction: 30 years of research in primary care.' Annual Review of Sociology. 32, $351-374$

Heritage J, Robinson J. (2006) The structure of patients’ presenting concerns. 1: Physicians’ opening questions. Health Communication. 19, 89- 102

Heritage, J. (2010) Questioning in Medicine. In Freed, A.F., Ehrlich, S., (eds.) Why Do You Ask?: The Function of Questions in Institutional Discourse. Oxford: University Press

Heritage, J. (2012) Epistemics in action: action formation and territories of knowledge. Research on Language and Social Interaction, 45, 1-29 
Hopper, R., Chen, C. H. (1996). Languages, cultures, relationships: Telephone openings in Taiwan. Research on Language and Social Interaction, 29, 291-313

Hutchby, I., (2005) Active Listening: Formulations and the elicitation of feeling-talk in child counseling. Research on Language and Social Interaction, 38, 303-329

Jefferson, G. (1983) Issues in the Transcription of Naturally-Occurring Talk: Caricature versus Capturing Pronunciational Particulars. Tilburg Papers in Language and Literature, 34, 1-12. Tilburg: Tilburg University

Johnson, A.J., Cotterill, J. (2002) So...? Pragmatic implications of so-prefaced questions in formal police interviews. In Janet Cotterill (ed) Language in the Legal Process. Palgrave: Basingstoke

Labov, W., Fanshel, D. (1977) Therapeutic discourse: psychotherapy as conversation. Academic Press. Orlando: Academic Press

Mandelbaum, J. (2003) Interactive methods for constructing relationships. In P. Glenn, C. D. LeBaron, \& J. Mandelbaum (Eds.), Studies in language and social interaction: In honor of Robert Hopper (pp. 207-219). Mahwah, NJ: Lawrence Erlbaum Associates, Inc.

The Merck Manual [electronic text book] (2012) Routine Psychiatric Assessment. Retrieved from 
http://www.merckmanuals.com/professional/psychiatric_disorders/approach_to_the_p atient_with_mental_symptoms/routine_psychiatric assessment.html

McCabe, R., Heath, C., Burns, T., Priebe, S., (2002) Engagement of Patients with Psychosis in the Consultation: A Conversation Analytic Study. British Medical Journal, 325, 1148-1151

McCabe, R., Leuder, I., Antaki, C. (2009) Do People with Schizophrenia Display Theory of Mind Deficits in Clinical Interactions? Psychological Medicine, 34, 401412

McCabe, R., Healey, P., Priebe, S., Bremner, S., Lavelle, M, Dodwell, D., Laugharne, R., , Snell, A., (2013) Shared Understanding in Psychiatrist-Patient Communication: Association with Treatment Adherence in Schizophrenia. Patient Education and Counseling, http://dx.doi.org/10.1016/j.pec.2013.05.015

National Institute for Health and Clinical Evidence (NICE) (2009) Schizophrenia: Core Interventions in the Treatment and Management of of Schizophrenia in Primary and Secondary Care. Guideline 82. London: NICE

National Institute for Health and Care Excellence. (2014) Standards and Indicators. Retrieved from https://www.nice.org.uk/standards-and-indicators 
Palmer, D. (2000) Identifying delusional discourse: Issues of rationality, reality and power. Sociology of Health \& Illness, 22: 661-678.

Palmer B.A., Pankratz. S., Bostwick J.M. (2005) The lifetime risk of suicide in schizophrenia. Archives of General Psychiatry, 62, 247-253

Priebe, S., Gruyters, T., (1993) The Role of the Helping Alliance in Psychiatric

Community Care: A Prospective Study. Journal of Nervous and Mental Disease. 181, $552-557$

Priebe, S., McCabe, R. (2006) The Therapeutic Relationship in Psychiatric Settings.

Acta Psychiatrica Scandinavica, 113, 69-72

Priebe, S., Dimic, S., Wildgrube, C., Jankovic, J., Cushing, A., McCabe, R. (2011)

Good Communication in Psychiatry: A Conceptual Review. European Psychiatry, 7: 403-7

Raymond, G. (2003) Grammar and Social Organization: Yes/No Interrogatives and the Structure of Responding. American Sociological Review, 68: 939-67

Raymond, G. (2006) Questions at Work: Yes/No Type Interrogatives in Institutional Contexts. In Paul Drew, Geoffrey Raymond, Darin Weinberg (eds.), Talk and

Interaction in Social Research Methods. London: Sage.

Raymond, G. (2010). Grammar and social relations: Alternative forms of Yes/No type

initiating actions in health visitor interaction. In Alice F. Freed and Susan Ehrlich 
(eds.), "Why Do You Ask?": The Function of Questions in Institutional Discourse New York: Oxford University Press, 87-107.

Robinson, J. (2006) Managing Trouble Responsibility and Relationships During Conversational Repair.”Communication Monographs 73, 137-161.

Robinson, J.D., Heritage, J. (2006) Physicians’ opening questions and patients' satisfaction. Patient Education and Counselling, 60, 279-85

Robinson, J. D., \& Kevoe-Feldman, H. (2010) Using full repeats to initiate repair on others' questions. Research on Language and Social Interaction, 43, 232-259.

Robinson, J. D. (2013). Epistemics, action formation, and other-initiation of repair: The case of partial questioning repeats. In M. Hayashi, G. Raymond \& J. Sidnell (Eds.), Conversational repair and human understanding. Cambridge: Cambridge University Press.

Ruusuvuori, J. (2005) Empathy and sympathy in action: attending to patients' troubles in Finnish homeopathic and general practice consultations. Social Psychology Quarterly, 68, 204-22

Ruusuvuori, J. (2007) Managing affect: integrating empathy and problem solving in two types of healthcare consultations. Discourse studies, 9, 597-622 
Sacks, H. (1987).On the Preferences for Agreement and Contiguity in Sequences in Conversation, In G. Button and J. R. E. Lee (eds.), Talk and Social Organisation. Clevedon, UK: Multilingual Matters

Sacks, H. (1992 [1964—72]). Lectures on Conversation, 2 vols. Oxford: Blackwell.

Schegloff, E.A. (1972) Notes on a conversational practice: Formulating place. IN D. Sudnow (ed) Studies in Social Interaction. (pp.289-237) New York: Free press.

Schegloff, E.A., Sacks, H., (1973) Open up Closings. Semiotica, 8, 289-327

Schegloff, E.A., (1984) On some questions and ambiguities in conversation. In J. Maxwell Atkinson and John Heritage (eds) Structures of Social Action. Cambridge: Cambridge University Press, 28-53

Schegloff, E.A. (1993) Reflections on Quantification in the Study of Conversation. Research on Language and Social Interaction, 26, 99-128.

Schegloff, E.A. (2000) When ‘others’ Initiate Repair. Applied Linguistics, 21, 205243

Schiffrin, D. (1987) Discourse Markers. New York: Cambridge University Press. Maxwell Atkinson and John Heritage (eds) Structures of Social Action. (pp. 28-53) Cambridge: Cambridge University Press 
Schegloff, E.A. (1996) Confirming Allusions: towards an empirical account of action. American Journal of Sociology, 104, 161-216

Schegloff, E.A., (2007) Sequence Organization in Interaction: A Primer in Conversation Analysis, Volume 1, Cambridge: Cambridge University Press

Stiver, T. (2015) Coding Social Interaction: A Heretical Approach in Conversation Analysis? Research on Language and Social Interaction, 48, 1, 1-19

Stivers, T., Rossano, R.F., (2010) Mobilising response. Research on Language and Social Interaction, 43, 1, 3-31

Suchman, L., Markakis, K., Beckman, H., Frankel, R. (1997) A mode of empathic communication in the medical interview. Journal of the American Medical Association, 4, 1680-1681

Ten Have, P. (1999/2007) Doing conversation analysis: A practical guide. London: Sage.

Thompson, L., McCabe, R. (2012) The Effect of Clinician-Patient Communication on Treatment Adherence in Mental Health Care: A Systematic Review. BMC Psychiatry, 12, 87 
Thompson, L., Howes, C., McCabe, R. (2015 In press) The Effect of Questions used by Psychiatrists on Therapeutic Alliance and Adherence. British Journal of Psychiatry

Turkington, D., Siddle, R. (1998) Cognitive Therapy for the Treatment of Delusions. Advances in Psychiatric Treatment, 4, 235-242

Van Os, J., Kapur, S. (2009) Schizophrenia. Lancet, 374, 635-645

Weiden P., Olfson M. (1995) Cost of relapse in schizophrenia. Schizophrenia Bulletin, 21, 419 - 429

\section{Recommended reading}

Thompson, L., Howes, C., McCabe, R. (2015 In press) The Effect of Questions used by Psychiatrists on Therapeutic Alliance and Adherence. British Journal of Psychiatry

Antaki, C. (2008) Formulations in psychotherapy. In A. Peräkylä, C. Antaki, S Vehviläinen and I Leudar (eds.) Conversation Analysis of Psychotherapy, Cambridge. England; CUP. 